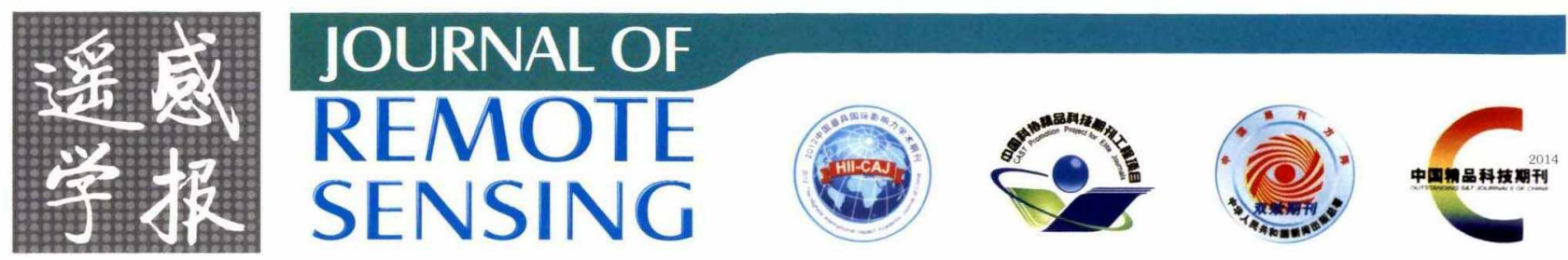

\title{
《遥感学报》编辑出版委员会
}

The Editorial Board of the Journal of Remote Sensing

\section{( 按拼音排序)}

( In Alphabetical Order)

\section{主任委员 Chairman \\ 徐冠华 XU Guanhua}

副主任委员 Vice Chairman

$\begin{array}{ll}\text { 陈宜元 } & \text { CHEN Yiyuan } \\ \text { 李德仁 } & \text { LI Deren } \\ \text { 栾恩杰 } & \text { LUAN Enjie } \\ \text { 田国良 } & \text { TIAN Guoliang } \\ \text { 许健民 } & \text { XU Jianmin } \\ \text { 周成虎 } & \text { ZHOU Chenghu }\end{array}$

\begin{tabular}{|c|c|}
\hline 纪原 & LIU Jiyuan \\
\hline K青 & SONG Changqing \\
\hline & WANG Jianyu \\
\hline 《祺 & XUE Yongqi \\
\hline
\end{tabular}

烡健雅 GONG Jianya

刘纪远 LIU Jiyuan

孙家栋 SUN Jiadong

吴一戎 WU Yirong

杨明辉 YANG Minghui

\author{
郭华东 GUO Huadong \\ 刘燕华 LIU Yanhua \\ 孙来燕 SUN Laiyan \\ 徐希孺 XU Xiru \\ 曾 澜 ZENG Lan
}

名誉主编 Honorary Editor in Chief

童庆禧 TONG Qingxi

首席顾问 General Advisor

高 炜 GAO Wei

主 编 Editor in Chief

顾行发 GUXingfa

副主编 Associate Editor in Chief

李增元 LI Zengyuan

邬伦 WU Lun

赵干钧 ZHAOQianjun

编 委 Members

$\begin{array}{ll}\text { 陈 晋 } & \text { CHEN Jin } \\ \text { 邓孺孺 DENG Ruru } \\ \text { 黄 波 HUANG Bo } \\ \text { 金亚秋 JIN Yaqiu } \\ \text { 李召良 LI Zhaoliang } \\ \text { 刘高焕 LIU Gaohuan } \\ \text { 秦其明 } \\ \text { 童 玲 } & \text { TONG Liming } \\ \text { 王 平 WANG Ping } \\ \text { 杨 凯 YANG Kai } \\ \text { 张国成 ZHANG Guocheng }\end{array}$

编辑部 Editorial Office

边 钊 BIAN Zhao
田庆久 TIAN Qingjiu 王锦地 WANG Jindi

间珺 (专职) YAN Jun (Full time) 张继贤 ZHANG Jixian

$\begin{array}{llll}\text { 陈镜明 } & \text { CHEN Jingming } & \text { 陈圣波 } & \text { CHEN Shengbo } \\ \text { 邸凯昌 } & \text { DI Kaichang } & \text { 范一大 } & \text { FAN Yida } \\ \text { 黄诗峰 } & \text { HUANG Shifeng } & \text { Jean Sequeira } \\ \text { 黎 夏 } & \text { LI Xia } & \text { 李 岩 } & \text { LI Yan } \\ \text { 梁顺林 } & \text { LIANG Shunlin } & \text { 林 珲 } & \text { LIN Hui } \\ \text { 刘学工 } & \text { LIU Xuegong } & \text { 卢乃锰 } & \text { LU Naimeng } \\ \text { 邵 芸 } & \text { SHAO Yun } & \text { 施建成 } & \text { SHI Jiancheng } \\ \text { 王 超 } & \text { WANG Chao } & \text { 王劲峰 } & \text { WANG Jinfeng } \\ \text { 王 桥 } & \text { WANG Qiao } & \text { 王智勇 } & \text { WANG Zhiyong } \\ \text { 杨 昆 } & \text { YANG Kun } & \text { 余 涛 } & \text { YU Tao } \\ \text { 张增祥 } & \text { ZHANG Zengxiang } & \text { 赵冬至 } & \text { ZHAO Dongzhi }\end{array}$

吴炳方 WU Bingfang

张良培 ZHANG Liangpei
党安荣 DANG Anrong

宫 鹏 GONG Peng

蒋兴伟 JIANG Xingwei

李加洪 LI Jiahong

林明森 LIN Mingsen

Paul F. Uhlir

孙国清 SUN Guoqing

王晋年 WANG Jinnian

阎广建 YAN Guangjian

张 兵 ZHANG Bing

赵忠明 ZHAO Zhongming 